\title{
Results of spinal cord decompression and thoracolumbar pedicle stabilisation in relation to the time of operation
}

\author{
C Gaebler ${ }^{1}$, R Maier ${ }^{1}$, F Kutscha-Lissberg ${ }^{1}$, L Mrkonjic $^{1}$ and V Vècsei ${ }^{1}$ \\ ${ }^{1}$ University of Vienna, Clinic for Trauma Surgery, Währinger Gürtel 18-20, A-1090 Vienna, Austria
}

\begin{abstract}
Short-segment pedicle stabilisation, transpedicular disc resection and autologous cancellous bone grafting is performed in trauma patients being transferred to our trauma centre with thoracolumbar fracture/dislocations. A follow-up examination of 88 patients, who were operated during the years of 1985-1992, took place after an average time of 5.6 years. Our results suggest that the earlier operative decompression and spine stabilisation takes place, the better is the recovery rate in patients with neurologic deficits. The highest neurologic recovery rates were found in patients operated within $8 \mathrm{~h}$ after the initial trauma. High remission rates were still found, if the patients had been operated within $48 \mathrm{~h}$. After this time there was no significant difference in the neurologic outcome compared to the time of operation.
\end{abstract}

Keywords: thoracolumbar fractures; spinal cord decompression; pedicle stabilisation; neurologic recovery

\section{Introduction}

With the introduction of the fixateur interne by Dick (1982) the first angular and rotational stable, dorsal spine implant had been introduced. ${ }^{1}$ Contrary to the extensive multi-level Harrington system ${ }^{2-5}$ a short segment instrumentation and stabilisation of the traumatised spine was made possible. The fixateur interne was the further development of Magerl's fixateur externe $e^{6,7}$ and of pedicular plate osteosyntheses. The minimal traumatising operation, the easy handling of the system and excellent short time results achieved by the fixateur interne, subsequently led to the development of several similar pedicle implants in the last years. ${ }^{1,6-12}$ Nevertheless, the efficiency of a dorsal stabilisation of thoracolumbar spine injuries by pedicle instrumentation is disputed. Series of complications (loss of reduction, non-union, failure of implants) concerning the dorsal stabilisation are discussed in literature. ${ }^{10,13}$ Some authors are convinced that decompression and stabilisation of the traumatised spine can only be achieved by an anterior approach. ${ }^{14-19}$ Some authors are even convinced that spine injuries of patients with a complete neurologic deficit after spine trauma must not be stabilised, because of the complications to be expected. ${ }^{1,6,15,20}$ However, the main discussion nowadays is the timing of spinal cord decompression and stabilisation in patients with thoracolumbar fractures and neurologic deficits. ${ }^{2,9,14-26}$

This retrospective study presents long term results and recovery rates of patients with and without neurologic deficits, after short segment pedicle

Correspondence: C Gaebler, University of Vienna, Clinic for Trauma Surgery, Währinger Gürtel 18-20, A-1090 Vienna, Austria instrumentation in relation to the time of the operation.

\section{Material and methods}

One hundred and seventeen patients with thoracolumbar fracture/dislocations in the years 1985-1992 were stabilised by short segment pedicle instrumentation (AO fixateur interne, Kluger fixateur interne, VSP instrumentation) by 12 different surgeons. Indication for decompression of the spinal cord and pedicle stabilisation of the spinal column were unstable spinal injuries, dislocations, spinal injuries with neurologic deficits and open fractures. These injuries were treated as emergencies, so that the operation is accomplished as soon as possible.

Fourteen patients had died by follow up. Seven of these had been polytraumatised. Death occurred because of pulmonary complications and multiple organ failure (MOF). Seven had died an age or cancer related death. Fifteen patients did not respond to follow-up letters. Eighty-eight patients (56 men $(64 \%)$ and 32 women $(26 \%)$ with an average age of 32.6 years at the time of the spinal injury) were followed up at an average of 5.6 years (1.9-9.3 years) after the initial spinal trauma. Motor vehicle or (motor) bike accident was the mechanism of injury in more than $50 \%$ of the cases. Fifty-four patients $(61.4 \%)$ suffered from 106 additional injuries, mainly throacic $(22 \%)$ and cranio-cerebral $(19 \%)$ trauma. Further injuries were fractures of long bones $(11 \%)$, fracturers of tarsal (mainly calcaneus) bones (16\%), pelvic fractures $(10 \%)$ and intraabdominal injuries $(5 \%)$. Fourteen patients $(15.9 \%)$ were polytraumatised 
with an average Hannover polytrauma score (HPTS) of 30.3 , respectively an average Injury severity score (ISS) of 44.8. In 18 patients $(20.5 \%)$ additional operations (plate and screw fixation, intramedullary nailing, skull trepanation, laparatomy) had to be performed. Eight patients $(10.5 \%)$ in motor vehicle accidents were obviously intoxicated with alcohol when arriving at the emergency room. Fifty-one patients $(58 \%)$ arrived after an average time of $48 \mathrm{~min}(0: 15-3.30 \mathrm{~h})$ after accident at our clinic. Thirty-seven patients $(42 \%)$ were transferred to our clinic from peripheral hospitals. Eleven of these patients $(12.5 \%)$ arrived on the day of their accident. Twenty-six patients $(30 \%)$ arrived at our clinic after an average time of 30.9 days ( $1-205$ days). Fortythree patients $(49 \%)$ had an incomplete and 24 patients $(27 \%)$ had a complete paraplegia (Table 1 ). Twenty-one patients (24\%) showed no neurologic deficits.

All 88 patients underwent posterior pedicle instrumentation and short segment (one or two segment) fusion (Figures 1-3). In patients with unstable fractures and/or neurologic deficits an immediate closed reduction in traction and lordosis was performed after imaging. The operation consisted of distraction via ligamentotaxis and restoration of the natural lordosis by pedicle screws. If initial CT scans revealed intraspinal posterior wall fragments, we performed a hemilaminectomy and direct decompression of the spinal canal. After reduction of the

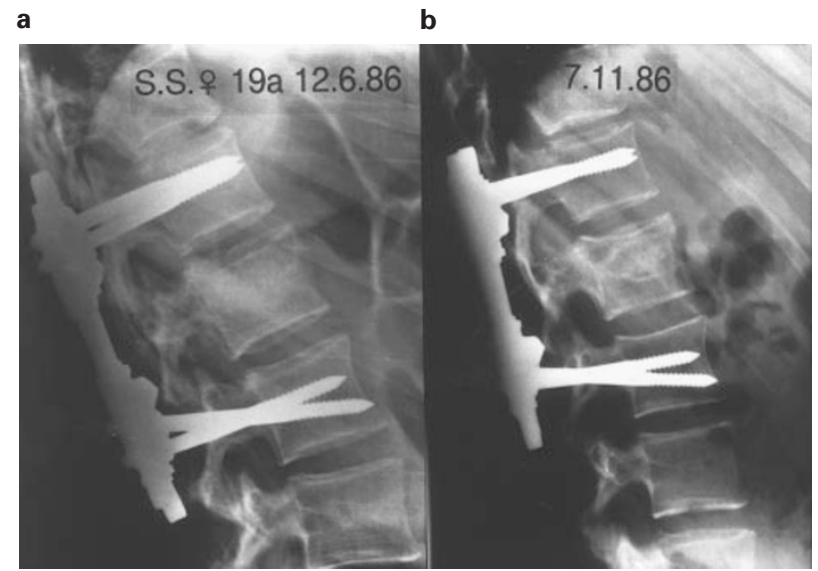

Figure $2(\mathbf{a}-\mathbf{b})$ The patient was operated 7 days after trauma (pedicle instrumentation, spinal cord decompression, transpedicular cancellous bone grafting) with an excellent result (SI 0.96, kyphosis $-3^{\circ}$ )-the control X-ray after 5 months (b) shows no signs of loss of reduction

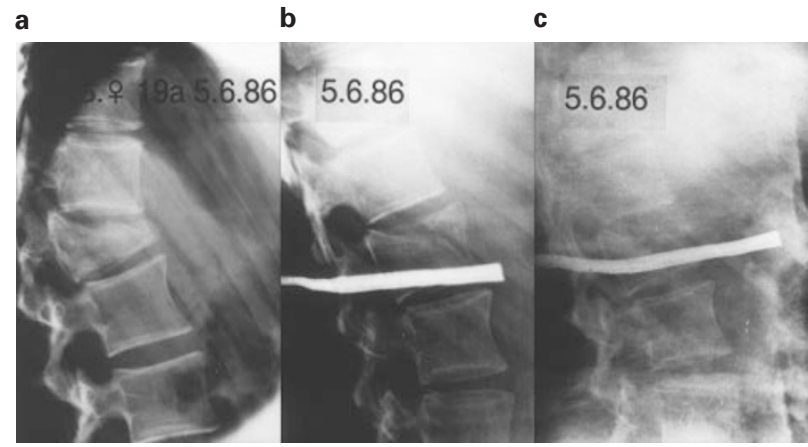

Figure $1(\mathbf{a}-\mathbf{c})$ The left X-ray shows the thoraco-lumbar spine of an 18 year old girl who jumped out of the window. The result was a complete burst fracture of the first lumbar vertebral body with an SI index of 0.32 respectively a kyphosis of $22^{\circ}$. The spinal canal compromise was $50 \%$-the patient showed no signs of a neurologic deficit. The initial conservative treatment happened at a peripheral hospital. After further X-rays showed that there was a significant loss of reduction under conservative treatment in this highly unstable situation - the patient was transferred to our trauma centre

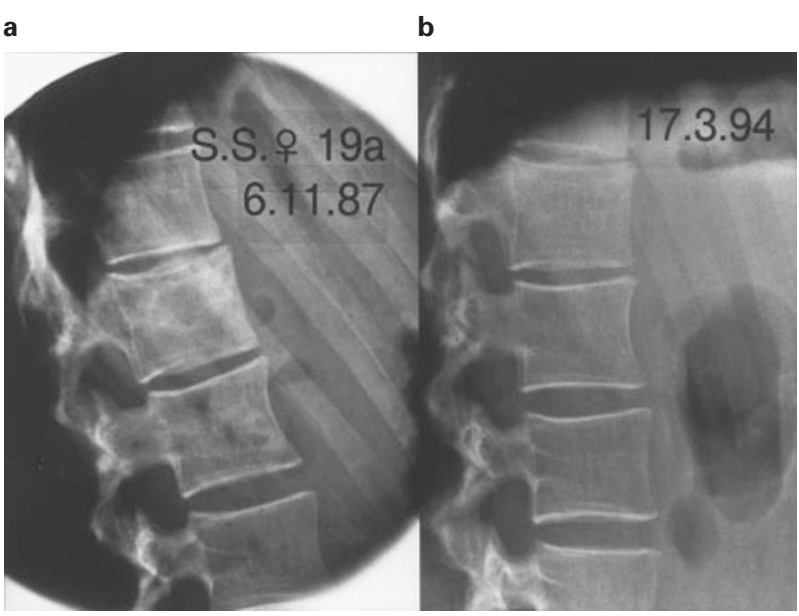

Figure 3 (a-b) Control X-rays after removal of the implants and at the time of follow-up show a minimal loss of reduction (SI 0.92, kyphosis, $0^{\circ}$ ), the patient complains only about occasional pain after physical exercise

Table 1 Primary neurologic deficit

\begin{tabular}{lccc}
\hline Neurologic deficit & Group 1 $(\mathrm{n}=26)$ & Group 2(n=50) & Group 3 (n=12) \\
\hline Complete paraplegia (Frankel A) & $10(38 \%)$ & $12(24 \%)$ & $2(16 \%)$ \\
Incomplete paraplegia (Frankel B-D) & $14(54 \%)$ & $24(48 \%)$ & $5(42 \%)$ \\
No neurologic deficit (Frankel E) & $2(8 \%)$ & $14(28 \%)$ & $5(42 \%)$ \\
\hline
\end{tabular}

Group 1: operation within 8 h; Group 2: operation after 8 h, but within 10 days; Group 3: operation after 10 days 
posterior wall fragment the destroyed disc was resected by a transpedicular approach, utilising a drill hole through one of the pedicles of the injured vertebral body. Autologous cancellous bone grafting ${ }^{8}$ with small iliac crest cancellous bone chips was performed by the same approach. After bone grafting the posterior wall reduction was examined with a nerve hook by the hemilaminectomy approach. Postoperatively the result of reduction was evaluated by CT scan. Early postoperative mobilisation started once the drains were removed and the patients fixed with a light orthosis for 3 months.

The follow-up examinations were performed by a trauma resident, who was not involved in the initial care of the patients. Spinal radiographs of the upright patient in anterioposterior and lateral planes were performed. The evaluation of the radiographs was based on sagittal index (SI) - SI index $=$ anterior vertebral height/posterior vertebral height, ${ }^{9}$ on kyphosis and scoliosis angle. A neurological and functional examination and a general interview were conducted. The classification of neurologic deficits is based on the Frankel Classification. ${ }^{24}$

The patients of the follow-up examination were subdivided into three groups (Table 1) according to the time of operation: Group I: operation within $8 \mathrm{~h}$ after the accident. Group II: operation after $8 \mathrm{~h}$, but within 10 days. Group III: operation after a time of 10 days.

Statistical comparisons were made with Chi-square and $t$-tests. For all statistical tests, significance was defined as $P<0.05$.

\section{Results}

Twenty-six patients $(29.6 \%)$ were operated within $8 \mathrm{~h}$ after the accident (Group 1), 50 patients $(56.8 \%)$, were operated after $8 \mathrm{~h}$ (Group II) and 12 patients (13.6\%) were operated after a time of 10 days (Group III). All the patients of Group III had been transferred to our clinic from peripheral hospitals after an average time of 55.9 days $(11-205$ days). Thirty-one patients $(35.2 \%)$ were transferred immediately post-operatively to an intensive care unit for an average time of 9.6 days (143 days). The average duration of hospitalisation was 27.3 days (4-101 days). There is a direct correlation between the length of hospitalisation and patients with additional injuries. Patients without additional injuries only stayed for an average time of 15.9 days at the hospital.

Operative stabilisation took place after an average time of 13.4 days $(0-207$ days). Patients with neurologic deficits were operated on as soon as possible (Table 1 ). Only $7.7 \%$ of the patients operated within $8 \mathrm{~h}$ were without neurologic deficits. Our results regarding neurologic recovery rates demonstrated three facts. First, patients of Group I demonstrated a rate of neurological recovery significantly higher $(P<0.001)$ than the patients of Groups II and III (Table 2). One patient out of Group I even showed a remission of complete tetraplegia up to a neurological situation of Frankel grade D. Second, patients with incomplete neurologic deficits of Frankel grades B-D, who showed a complete remission of their neurologic deficits to Frankel grade $\mathrm{E}(n: 21)$, had been operated within an average time of $36 \mathrm{~h}(P<0.0001)$. Third, all patients with incomplete paraplegia, who were operated within $48 \mathrm{~h}(P<0.001)$ showed a remission of at least one Frankel grade. In patients operated later on there was no significant difference of neurologic recovery rates.

The fracture clasification (Table 3) is based on the McAfee classification. $5,7,18$ Regarding the anatomic level we found five fractures $(5.7 \%)$ at $\mathrm{T} 10$, eight fractures $(9.1 \%)$ at $\mathrm{T} 11,21$ fractures $(23.8 \%)$ at $\mathrm{T} 12$, 34 fractures $(38.6 \%)$ at L1, 13 fractures $(14.8 \%)$ at L2 and seven fractures $(7.9 \%)$ at L3. Contrary to our expectations we found no significant difference in the extent of neurological recovery in respect to the level of spinal cord injury (cephalad to T12, conus and epiconus, cauda equina).

The results of the postoperative reduction with an average sagittal $(\mathrm{SI})$ index $^{1,8}(\mathrm{SI}=$ anterior vertebral height/posterior vertebral height) of 0.90 were absolutely satisfying (Table 4). Groups I and II showed a slight difference in the percental reduction $\left(\mathrm{xx}^{\circ} \%=\mathrm{SI}\right.$ postoperatively $\times 100 /$ SI preoperatively) of the vertebral body (Group I: 60.7\%; Group II: 51.7\%), but this was mainly based on the primary difference of the SI index (Table 4). The postoperative reduction results (Group I: SI 0.90, Group II: SI 0.91) were similar in both Groups. In Group III an operative reduction of

Table 2 Frankel classification and development of neurologic deficit

\begin{tabular}{|c|c|c|c|c|c|c|c|c|c|}
\hline \multirow[b]{2}{*}{ Grading } & \multicolumn{3}{|c|}{$\begin{array}{c}\text { Group } 1(\mathrm{n}=26) \\
6 \text { month }\end{array}$} & \multicolumn{3}{|c|}{$\begin{array}{c}\text { Group } 2(\mathrm{n}=50) \\
6 \text { month }\end{array}$} & \multicolumn{3}{|c|}{$\begin{array}{c}\text { Group } 3(\mathrm{n}=12) \\
6 \text { month }\end{array}$} \\
\hline & Prim. & control & Follow up & Prim. & control & Follow up & Prim. & control & Follow up \\
\hline A & $10(38.5 \%)$ & $9(34.6 \%)$ & $9(34.6 \%)$ & $12(24.0 \%)$ & $12(24.0 \%)$ & $12(24.0 \%)$ & $2(16.7 \%)$ & $2(16.7 \%)$ & $2(16.7 \%)$ \\
\hline B & $9(34.6 \%)$ & $1(3.85 \%)$ & - & $12(24.0 \%)$ & $1(2.0 \%)$ & - & $1(8.3 \%)$ & $1(8.3 \%)$ & - \\
\hline $\mathrm{C}$ & $2(7.7 \%)$ & $4(15.4 \%)$ & $1(3.85 \%)$ & $7(14.0 \%)$ & $5(10.0 \%)$ & $1(2.0 \%)$ & $4(33.3 \%)$ & $1(8.3 \%)$ & $2(16.7 \%)$ \\
\hline $\mathrm{D}$ & $3(11.5 \%)$ & $7(26.9 \%)$ & $7(26.9 \%)$ & $5(10.0 \%)$ & $13(26.0 \%)$ & $12(24.0 \%)$ & - & $3(25.0 \%)$ & - \\
\hline E & $2(7.7 \%)$ & $5(19.25 \%)$ & $9(34.6 \%)$ & $14(28.0 \%)$ & $19(38.0 \%)$ & $25(50.0 \%)$ & $5(41.7 \%)$ & $5(41.7 \%)$ & $8(66.6 \%)$ \\
\hline
\end{tabular}

Group 1: operation within 8 h; Group 2: operation after 8 h, but within 10 days; Group 3: operation after 10 days 
Table 3 Fracture classification (McAfee)

\begin{tabular}{lccc}
\hline Type of fracture & Group $1(\mathrm{n}=26)$ & Group 2 $(\mathrm{n}=50)$ & Group $3(\mathrm{n}=12)$ \\
\hline Wedge compression fracture & $2(7.7 \%)$ & $4(8.0 \%)$ & $1(8.3 \%)$ \\
Incomplete burst fracture & $8(30.75 \%)$ & $10(20.0 \%)$ & $5(41.7 \%)$ \\
Complete burst fracture & $4(15.4 \%)$ & $20(40.0 \%)$ & $2(16.7 \%)$ \\
Flexion-distraction injury & $8(30.75 \%)$ & $10(20.0 \%)$ & $3(25.0 \%)$ \\
Translational injury & $4(15.4 \%)$ & $6(12.0 \%)$ & $1(8.3 \%)$ \\
Chance fracture & - & - & -
\end{tabular}

Group 1: operation within 8 h; Group 2: operation after 8 h, but within 10 days; Group 3: operation after 10 days

Table 4 Mean radiographic measurements

\begin{tabular}{|c|c|c|c|}
\hline & Group $1(\mathrm{n}=26)$ & Group $2(\mathrm{n}=50)$ & Group $3(\mathrm{n}=12)$ \\
\hline \multicolumn{4}{|l|}{ Average SI index* } \\
\hline SI preoperatively & $0.56(0.37-0.96)$ & $0.60(0.52-0.96)$ & $0.53(0.32-0.87)$ \\
\hline SI postoperatively & $0.90(0.79-0.96)$ & $0.91(0.83-0.96)$ & $0.86(0.72-0.91)$ \\
\hline SI at follow up & $0.85(0.62-0.92)$ & $0.84(0.57-0.96)$ & $0.73(0.43-0.94)$ \\
\hline \multicolumn{4}{|c|}{ Average kyphosis (Cobb method) } \\
\hline Kyphosis preoperatively & $18.74(10-32)$ & $18.83(0-41)$ & $15.82(0-28)$ \\
\hline Kyphosis postoperatively & $0.82(-3-16)$ & $0.47(-8-12)$ & $1.53(-5-12)$ \\
\hline Kyphosis at follow up & $4.62(-2-20)$ & $5.99(0-26)$ & $13.37(0-30)$ \\
\hline \multicolumn{4}{|l|}{ Average scoliosis } \\
\hline Scoliosis preoperatively & $4.8(0-20)$ & $5.2(0-24)$ & $8.8(0-30)$ \\
\hline Scoliosis postoperatively & $0.3(0-6)$ & $0.3(0-8)$ & $2.1(0-14)$ \\
\hline Scoliosis at follow up & $1.1(0-10)$ & $1.8(0-20)$ & $4.1(0-24)$ \\
\hline
\end{tabular}

*SI index $=$ anterior vertebral height/posterior vertebral height. Group 1: operation within 8 h; Group 2: operation after 8 h, but within 10 days; Group 3: operation after 10 days

SI 0.86 had been achieved by pedicle instrumentation. This result is significantly $(P<0.001)$ below the results of Groups I and II. At the follow-up examination Group II displayed a loss of reduction based on the SI index of $7.7 \%$, meanwhile Group I presented a loss of reduction of only $5.6 \%(P<0.1)$. Group III showed a significant $(P<0.00001)$ loss of reduction of $15.1 \%$ resulting in a follow-up SI-Index of only 0.73 .

The differences between the three Groups are shown even more clearly by the variation of the kyphosis angle $(\mathrm{xx} \%=100-[\mathrm{kyphosis}$ postoperatively $\times 100 /$ kyphosis preoperatively]). In Group I (Table 4) a postoperative reduction of $95.7 \%$ had been achieved, in Group II even 97.6\%. In Group III a reduction of $90.3 \%$ was operatively achieved. The loss of reduction until the follow up examination was $20.3 \%$ in Group I, $29.3 \%$ in Group II and $74.8 \%$ in Group III $(P<0.00001)$. A complete reduction of the traumatological scoliosis $\left(\mathrm{xx}_{0}=100-\right.$ [scoliosis postoperatively $\times 100$ /scoliosis preoperatively]) could not be achieved in any of the three Groups, but a reduction of $93.7 \%$ in Group I and a reduction of $94.2 \%$ in Group II was possible. In Group III $76.1 \%$ of operative reduction of scoliosis were achieved. The loss of reduction until follow up in the sagital plane was $16.7 \%$ in Group I, $28.8 \%$ in Group II and $22.7 \%$ in Group III.
The majority of the patients were without pain at rest and every day lives. Some complained about pain occasionally (Table 5). Only one patient complained about pain at rest. An MRI scan showed remaining parts of the destroyed discus in the once fractured vertebral body and a chronic inflammatory reaction. Thirty per cent of the patients complained about pain after physical exercise. Eight per cent of the patients sometimes took pain killers, but none of the patients needed analgesics continuously. The follow-up study shows that patients of Group III complained significantly $(P<0.001)$ more often about pain in rest, every day life and after physical exercise than the patients of Groups I and II. The patients of Group I obviously $(P<0.01)$ had fewer complaints than the patients of Group II. The finger-tip floor difference measured an average of $10.22 \mathrm{~cm}(0-50 \mathrm{~cm})$. Patients of groups I and II were significantly $(P<0.0001)$ better in their vertebral mobility compared to Group III. The average finger-tip floor difference of Group III was $19.5 \mathrm{~cm}$ and therefore three times worse than Group I $(\phi 6.42 \mathrm{~cm})$ and II $(\phi 5.87 \mathrm{~cm})$. Patients of Group III complained significantly $(P<0.001)$ more often $(33.3 \%)$ about pain in weather changes than the patients of Groups I $(23.1 \%)$ and Group II $(18.0 \%)$. Only $9.1 \%$ of the 88 patients complained about pain 
at the iliac crest sometimes. In one case an infected haematoma at the iliac crest had had to be evacuated.

\section{Complications and revision operations}

The rate of complications in the 88 patients of the follow up examination was $11.4 \%$ (Table 6). There were two cases $(2.2 \%)$ of non-union. In these two patients cadaver bone grafts had been used for transpedicular cancellous bone grafting. After reoperation and autologous cancellous bone grafting, and in one case new instrumentation, the further course was without complications. After these poor results only autologous cancellous bone was used further on. Nonunion did not occur in any of the following cases. In the two patients with non-union consecutive loosening of the implant occurred. Failure of the implant was the result in one of these cases so that one complication added up to another one. Further complications were persisting intraspinal bone fragments $(3.4 \%)$ with postoperative neurological deterioration and deep wound infections $(3.4 \%)$, which also led to consecutive loosening and failure of implants. A complication leading to another one was regarded as one complication.

Eight revision operations were performed:

- twice because of a non-union,

- three times because of a deep wound infection,

- three times, because the primary aim of operation had not been achieved.

In these cases remaining posterior wall fragments had to be reduced in a revision operation after the postoperative CT scan. A failure of one or more pedicule screws (once at T12, twice at L1, twice at L2 and twice at L3) occurred in six patients $(6.8 \%)$. This failure was based on overload in only one case, where it was related to a situation of non-union. In the other five patients a breakage of the pedicle screws occurred after bone healing, an average time of 19.3 months after fracture stabilisation, as a symptom of implant fatigue. No signs of instability were found clinically or radiologically. There was no significant relationship

Table 5 Pain

\begin{tabular}{|c|c|c|c|}
\hline & Group $1(\mathrm{n}=26)$ & Group $2(\mathrm{n}=50)$ & Group $3(\mathrm{n}=12)$ \\
\hline \multicolumn{4}{|l|}{ Pain in rest } \\
\hline No pain & $24(92.3 \%)$ & $46(92.0 \%)$ & $9(75.0 \%)$ \\
\hline Sometimes pain & $2(7.7 \%)$ & $3(6.0 \%)$ & $3(25.0 \%)$ \\
\hline Permanent pain/no analgesics & - & $1(2.0 \%)$ & - \\
\hline Permanent pain/sometimes analgesics & - & - & - \\
\hline Permanent pain/permanent analgesics & - & - & - \\
\hline \multicolumn{4}{|l|}{ Pain in everyday life } \\
\hline No pain & $18(69.3 \%)$ & $31(62.0 \%)$ & $6(50.0 \%)$ \\
\hline Sometimes pain & $4(15.4 \%)$ & $17(34.0 \%)$ & $2(16.7 \%)$ \\
\hline Permanent pain/no analgesics & $3(11.5 \%)$ & $2(4.0 \%)$ & $3(25.0 \%)$ \\
\hline Permanent pain/sometimes analgesics & $1(3.8 \%)$ & - & $1(8.3 \%)$ \\
\hline Permanent pain/permanent analgesics & - & - & - \\
\hline \multicolumn{4}{|l|}{ Pain after physical exercise } \\
\hline No pain & $14(53.9 \%)$ & $19(38.0 \%)$ & $3(25.0 \%)$ \\
\hline Sometimes pain & $5(19.2 \%)$ & $17(34.0 \%)$ & $4(33.33 \%)$ \\
\hline Permanent pain/no analgesics & $5(19.2 \%)$ & $10(20.0 \%)$ & $4(33.33 \%)$ \\
\hline Permanent pain/sometimes analgesics & $2(7.7 \%)$ & $4(8.0 \%)$ & $1(8.33 \%)$ \\
\hline Permanent pain/permanent analgesics & - & - & - \\
\hline
\end{tabular}

Group 1: operation within 8 h; Group 2: operation after 8 h, but within 10 days; Group 3: operation after 10 days

Table 6 Complications

\begin{tabular}{|c|c|c|c|c|}
\hline Complications & Total $(\mathrm{n}=88)$ & Group $1(\mathrm{n}=26)$ & Group $2(\mathrm{n}=50)$ & Group $3(\mathrm{n}=12)$ \\
\hline Non-union & $2(2.2 \%)$ & - & $2(4.0 \%)$ & - \\
\hline Loosening of implant & $4(4.5 \%)$ & $2(7.7 \%)$ & $2(4.0 \%)$ & - \\
\hline Failure of implant & $6(6.8 \%)$ & $1(3.8 \%)$ & $3(6.0 \%)$ & $2(16.7 \%)$ \\
\hline Deep wound infection & $3(3.4 \%)$ & $1(3.8 \%)$ & $2(4.0 \%)$ & - \\
\hline Persisting intraspinal bone fragment & $3(3.4 \%)$ & $2(7.7 \%)$ & $1(2.0 \%)$ & - \\
\hline
\end{tabular}

Group 1: operation within 8 h; Group 2: operation after 8 h, but within 10 days; Group 3: operation after 10 days 
between time of operation and occurrence of complications. In 33 cases $(37.5 \%)$ the implant was removed after an average time of 17.1 months.

\section{Discussion}

Fractures and dislocation fractures of the thoracolumbar spine are the most common osseous spine injuries and mainly occur in association with motor vehicle accidents. ${ }^{25,27-29}$ In about $60-70 \%$ of the cases the patients are afflicted with additional injuries. ${ }^{28}$ The advantage of an operative procedure concerning these injuries is the immediate stabilisation of the injured spine and a direct decompression of the spinal cord. Operative stabilisation allows an early mobilisation without a heavy and uncomfortable cast and evidently shortens the time of stay in the hospital.,7 The indication for an operative stabilisation in patients with unstable spine injuries and complete paraplegia is the prospect of an early rehabilitation and the easier care of these often polytraumatised patients. ${ }^{6,7,22,23,30,31}$

At our trauma centre short segment fusion by pedicle implants is the method of choice. Short segment fusion only preserves one or two motion segments, so that the mobility of the spinal column is hardly affected. To avoid pain and secondary loss of reduction transpedicular disc resection and autologous cancellous bone grafting are to be performed. ${ }^{1,6}$ Our study showed that the results of reduction in the patients operated within 10 days were excellent. A complete reduction by a posterior approach could not be achieved in patients who were operated after 10 days. The secondary loss of reduction is two to three times higher in this group compared to the patients treated within 10 days. McKinley found a loss of reduction of $18^{\circ}$ after short segment Cotrel-Dubousset instrumentation (in 13). These results were not seen in our patients after dorsal stabilisation and short segment pedicle instrumentation. It appeared that patients whose spine had been stabilised very early (Group I) showed not only better radiologic but also better functional results than patients who had been operated on late. The poorest functional results were to be found in the patients of Group III.

This and the obvious fact that a complete reduction cannot be achieved after a time of 10 days convinced us to perform anterior decompression and stabilisation in these cases. However, the main indication for an anterior approach are burst fractures with bony as well as disc fragments impinging on the neural tissue. In these cases a decompression of the spinal cord cannot be achieved by a posterior approach-that is why we suggest anterior decompression and stabilisation. A further indication for an anterior approach are massive vertebral burst fractures with a destruction of all three columns and translational vertebral injuries, which we see mainly in polytraumatised patients. In these cases we suggest short segment posterior stabilisation as emergency procedure and an anterior fusion when the patient's situation is stable.
Patients sometimes complain about pain at the iliac crest graft site after autologous cancellous bone grafting. Some authors even describe a frequency of pain of $6-25 \% .^{32,33}$ Therefore, and because of an allegedly increased infection rate of $3-9 \%$, some authors demand homologous cancellous bone graft or alternative materials. ${ }^{33}$ Our follow-up examination showed that on the one hand $91 \%$ of the patients had absolutely no complaints related to their graft site, on the other hand two patients suffered non-union after cadaver bone grafting.

Schlegel et $a l^{23}$ reported a lesser complication rate in patients with acute spinal fractures (cervical fractures down to L3 and below) who were stabilised within $72 \mathrm{~h}$ compared to patients operated later on. Contrary to their results we did not find any significant difference in the complication rates of our patients with thoracolumbar fractures in relation to the time of operation. A generally increased compli-cation rate after short segment pedicle fusion is occasionally reported in literature. ${ }^{10,13,26}$ We could not confirm these findings either. Especially complication rates of $26-46 \%$ as reported after Harrington instrumentation $^{2,5,26}$ did not occur in our patients. The non-union rate after pedicle instrumentation, literature reports non-union rates up to $40 \%$, was $2.2 \%$. The allegedly frequent failure of implants occurred only once in a patient with non-union before fracture consolidation took place. The other cases happened after fracture healing as a fatigue reaction of the implant and caused no signs of instability. A rate of implant failure of more than $50 \%$ as described by McLain et al ${ }^{10}$ did not occur in our patients. We suggest removal of the implant after radiologic and clinically confirmed fracture consolidation, normally after about 12 months. After 12 months the probability of implant fatigue increases and it is almost impossible to remove broken screws out of the pedicle canal.

Three cases $(3.4 \%)$ of persistent spinal cord compression led to a change of our operative management. At the end of the operation the spinal canal is examined once again by the flavectomy or hemilaminectomy approach to make sure that no posterior wall fragment was displaced by the transpedicular cancellous bone grafting. A myelography is not routinely performed, because of the well known complications and the uncertain radiologic results. ${ }^{10}$ Immediately after the operation the operative result is evaluated by $\mathrm{CT}$ scan to examine the spinal canal and to be able to react adequately to a deteriorating neurologic status in the patients' postoperative phase of awakening.

Our results suggest the importance of an early decompression of the spinal cord. The earlier the patients are operated, the better is the neurologic recovery rate. The highest recovery rates were found in patients operated within $8 \mathrm{~h}$ after the initial trauma. A complete remission of neurologic deficits (Frankel BD) was seen only in patients decompressed and stabilised within $36 \mathrm{~h}$. High remission rates were 
found, if the patients had been operated within $48 \mathrm{~h}$. After this time there was no significant difference in the neurologic outcome compared to the time of operation. The discussion of an emergency operation in patients with thoracolumbar fractures and neurologic deficits have been going on for years. Despite relatively small numbers of patients our results of this retrospective study point in the direction of an immediate spinal cord decompression and stabilisation. Strong support for our emergency management in spine fractures with neurologic deficits came from Dimes $^{21}$ who presented an animal study which showed that the earlier rats with clearly defined spinal cord compression underwent decompression the better were the neurologic recovery rates.

\section{References}

1 Dick W. The 'fixateur interne' as a versatile implant for spine surgery. Spine 1987; 12: $882-900$.

2 Böstman OM, Myllynen PJ, Riska EB. Unstable fractures of the thoracic and lumbar spine: the audit of an 8-years series with early reduction using Harrington instrumentarium. Injury 1987; 18: $190-195$

3 Dickson JH, Harrington RP, Erwin WD. Results of reduction and stabilization of the severely fractured thoracic and lumbar spine. J Bone Joint Surg Am 1978; 60: $799-805$.

4 Harrington PR. Instrumentation in spine instability other than scoliosis. S Afr J Surg 1967; 5: 7-12.

5 McAfee PC, Bohlman HH. Complications following Harrington instrumentation for fractures of the thoracolumbar spine. $J$ Bone Joint Surg Am 1985; 67: 672-685.

6 Kluger P, Gerner JH. Das mechanische Prinzip des Fixateur externe zur dorsalen Stabilisierung der Brust- und Lendenwirbelsäule. Unfallchirurgie 1986; 12: 68-79.

7 Magerl F. Der Wirbel-Fixateur externe. In: Weber BG, Magerle F (eds). Fixateur externe. Springer Berlin/Heidelberg/New York, 1985.

8 Daniaux H. Transpedikuläre Reposition und Spongiosaplastic bei Wirbelkörperbrüchen der unteren Brust- und Lendenwirbelsäule. Unfallchirurg 1986; 89: $197-213$.

9 Lindsey RW, Dick W. The Fixateur interne in the reduction and stabilization of thoracolumbar spine fractures in patients with neurologic Deficit. Spine 1991; 16S: 140-145.

10 McLain RF, Sparling E, Benson DR. Early failure of shortsegment pedicle instrumentation for thoracolumbar fractures. $J$ Bone Joint Surg Am 1993; 75: 162 - 167.

11 Ciapetta P, Delfini R, Costanzo G. Posterolateral decompression and stabilisation of thoracolumbar injuries Using Diapson Instrumentation. Acta Neurochir 1996; 138: 314-321.

$12 \mathrm{Wu}$ SS et al. Management of rigid post-traumatic kyphosis. Spine 1996; 21: $2260-2267$.

13 McCormack T, Karaikovic E, Gaines RW. The load sharing classification of spine fractures. Spine 1994; 19: $1741-1744$.
14 Bohlman HH. Treatment of fractures and dislocations of the thoracic and lumbar spine. J Bone Joint Surg Am 1985; 67: 165 169.

15 Bradford DS, McBride GG. Surgical management of thoracolumbar spine fractures with incomplete neurologic deficits. Clin Orthop 1987; 218: 201 - 216.

16 Dunn HK. Anterior spine stabilization and decompression for thoracolumbar injuries. Orthop Clin North Am 1986; 17: $113-$ 119.

17 Kaneda K, Abumi K, Fujiya M. Burst fractures with neurologic deficits of the thoracolumbar-lumbar spine: Results of anterior decompression and stabilization with anterior instrumentation. Spine 1984; 9: 788-795.

18 McAfee PC, Bohlman HH, Yuan HA. Anterior decompression of traumatic thoracolumbar fractures with incomplete neurological deficit using a retroperitoneal approach. J Bone Joint Surg Am 1985; 67: 89- 104

19 Riska EB, Myllynen P, Böstman O. Anterolateral decompression for neural involvement in thoracolumbar fractures. $J$ Bone Joint Surg $\mathrm{Br}$ 1987; 69: $704-708$.

20 Place HM, Donaldson DH, Brown CW, Stringer EA. Stabilization of thoracic spine fractures resulting in complete paraplegia. Spine 1994; 19: $1726-1730$.

21 Dimes T. The effect of early spinal cord decompression in rats. Introduction speech at the OTA-Meeting, Louisville, Kentucky 1997.

22 Waters RL, Adkins RH, Yakura JS, Sie I. Effect of surgery on motor recovery following traumatic spinal cord injury. Spinal Cord 1997; 34: 188-192.

23 Schlegel J, Bayley J, Yuan H, Fredricksen B. Timing of surgical decompression and fixation of acute spinal fracturs. J Orthop Trauma 1996; 5: 323 - 330.

24 Frankel HL et al. The value of postural reduction in the initial management of closed injuries of the spine with paraplegia and tetraplegia. Paraplegia 1969; 7: 179-192.

25 Reid DC, Hu R, Davis LA, Saboe LA. The nonoperative treatment of burst fractures of the thoracolumbar junction. $J$ Trauma 1988; 28: $1188-1194$.

26 Clohisy JC et al. Neurologic recovery associated with anterior decompression of spine fractures at the throacolumbar junction. Spine 1992; 17S: $325-330$.

27 Korovessis P, Sidiropoulos P, Dimas A. Complete fracturedislocation of the thoracic spine without neurologic deficit: Case report. J Trauma 1994; 36: $122-124$.

28 Saboe LA et al. Spine trauma and associated injuries. J Trauma 1991; 31: $43-48$.

29 Brandser EA, El-Khoury GY. Thoracic and spine trauma. Rad Clin Am 1997; 35: 533-557.

30 Jodoin A et al. Unstable fractures of the thoracolumbar spine: A 10-year experience at Sacré-Coeur Hospital. J Trauma 1985; 25: $197-201$

31 Abe E et al. Thoracolumbar burst fracture with horizontal fracture of the posterior column. Spine 1997; 22: 83-87.

32 Summers BN, Eisenstein SM. Donor site pain from the ilium. A complication of lumbar spine fusion. J Bone Joint Surg Br 1989 71: $677-680$

33 Cook SD et al. In vivo evaluation of recombinant human osteogenic protein (rhOP-1) implants as a bone graft substitute for spinal fusion. Spine 1994; 19: 1655-1663. 